Research Paper

\title{
Comparison of lodine- 125 Seed Implantation and Pancreaticoduodenectomy in the Treatment of Pancreatic Cancer
}

\author{
Kai Liu*, Bai Ji*, Wei Zhang, Songyang Liu, Yingchao Wang, Yahui Liu ${ }^{凶}$ \\ Department of Hepatobiliary and Pancreatic Surgery, the First Bethune Hospital, Jilin University, Jilin 130021, China. \\ * contributed equally to this paper.
}

$\square$ Corresponding author: Yahui Liu, PhD. MD. Department of Hepatobiliary and Pancreatic Surgery, the First Bethune Hospital, Jilin University, Jilin 130021, China (Tel: 86-431-81875160; E-mail:liuyahui2008@yeah.net).

(C) Ivyspring International Publisher. This is an open-access article distributed under the terms of the Creative Commons License (http://creativecommons.org/ licenses/by-nc-nd/3.0/). Reproduction is permitted for personal, noncommercial use, provided that the article is in whole, unmodified, and properly cited.

Received: 2014.02.27; Accepted: 2014.05.29; Published: 2014.06.20

\begin{abstract}
Objective: This retrospective study compared the advantages and disadvantages of iodine- 125 (I25I) seed implantation and pancreaticoduodenectomy (PD) in the treatment of pancreatic cancer.

Methods: Patients with diagnosed pancreatic cancer who were treated with $125125 \mid$ seed implantation (30 patients) or PD (30 patients) in our hospital were evaluated for operative time, bleeding, liver function, time to first bowel movement and normal diet, survival, and medical costs.

Results: Compared with patients who underwent PD, those given 1251 seed implantation had significantly shorter operative time, less bleeding, higher albumin, shorter periods to bowel movement and normal diet, lower risk of complications, and lower medical costs $(P<0.00 \mathrm{I}$, each). The difference of bilirubin level, time to feeding, and median survival were not significant statistically between two treatment grouops.

Conclusion: For pancreatic cancer patients for whom PD is not appropriate or who refuse PD, I25I seed implantation is a good option.
\end{abstract}

Key words: pancreatic cancer; 125 I seed implantation; pancreaticoduodenectomy; radiotherapy.

\section{Introduction}

Pancreatic cancer is the fourth leading cause of cancer-related deaths in the United States and the eighth worldwide. The disease has an extremely poor prognosis because of the lack of early diagnostic symptoms and resistance to conventional chemo- and radiotherapies ${ }^{1,2}$. Pancreaticoduodenectomy (PD), also known as the Whipple procedure, is the standard curative surgical treatment for cancers of the head of the pancreas. The surgery is complex, involving the removal of several organs (partial stomach, partial duodenum, and head of the pancreas, bile duct, and gallbladder) and the construction of a bypass for food. The high risk and cost of the PD is such that some patients refuse to undergo the procedure ${ }^{3,4}$. Some studies have suggested that intraoperative ultrasound-guided iodine-125 (125I) seed implantation is a feasible and safe alternative to PD for managing unresectable pancreatic carcinoma ${ }^{5,6}$. However, the efficacy of ${ }^{125} \mathrm{I}$ seed implantation relative to PD for the treatment of pancreatic cancer has not been determined.

In this retrospective study, using the database of our hospital from September 2010 to September 2013, we compared the clinicopathological parameters of PD-treated pancreatic cancer patients to those of patients treated with ${ }^{125}$ I seed implantation. 


\section{Materials and Methods}

\section{Patient enrollment and assessment}

Sixty patients were retrospectively included in this study (Table 1). In 125I-treated patients, the surgery procedure was determined based on the presence of jaundice and gastrointestinal obstruction. The pancreatic cancer in all patients was diagnosed by computed tomography scan and FNA biopsy during operation for implantation group. A pulmonary function test was performed in patients over 55 years old or with a history of smoking, and the breathing reserve ratio was greater than $57 \%$. No cardiovascular complications or liver or kidney dysfunction was observed in any of the patients. The ethics committee of our hospital approved this study, and oral consent for publication of clinical data was obtained from all patients. All patients were early stage with TNM stage I and stage II, but some patients chose to do ${ }^{125}$ I seed implantation because they could not afford high medical expenses or with other diseases.

Table I. Patient information.

\begin{tabular}{|c|c|c|c|c|}
\hline Treatment & $\begin{array}{l}\text { Average } \\
\text { Age (y) }\end{array}$ & Male/female & Details & $\mathrm{n}$ \\
\hline \multirow{3}{*}{$\begin{array}{l}\text { 125I seed } \\
\text { implantation }\end{array}$} & 38 & $18 / 12$ & 125I seed implantation only & 11 \\
\hline & & & $\begin{array}{l}\text { 125I seed implantation + chole- } \\
\text { dochoduodenostomy }\end{array}$ & 9 \\
\hline & & & $\begin{array}{l}\text { 125I seed implantation }+ \text { chole- } \\
\text { dochoduodenostomy }+ \text { gastrointes- } \\
\text { tinal anastomosis }\end{array}$ & 10 \\
\hline PD & 42 & $19 / 11$ & & 30 \\
\hline
\end{tabular}

\section{Procedure for $125 \mathrm{I}$ seed implantation}

Once the diagnosis of pancreatic cancer was confirmed, tumor volume was measured during laparotomy by intraoperative ultrasonography utilizing a megahertz linear probe. The procedure for ${ }^{125} \mathrm{I}$ (China Isotope \& Radiation, Beijing, China) seed implantation was carried out as previously described ${ }^{5,6}$. Briefly, under the guidance of ultrasound, 18-gauge needles were inserted into the tumor mass at intervals of $1.0 \mathrm{~cm}$ in a parallel array, extending at least 0.5 to $1.0 \mathrm{~cm}$ beyond the margins of pancreatic lesions. Penetration of the pancreatic duct, small blood vessels, and adjacent transverse colon was avoided. After the needles were placed, ${ }^{125}$ I seeds were implanted using a Mick applicator and the spacing was maintained at $1.0-\mathrm{cm}$ intervals. The number of ${ }^{125} \mathrm{I}$ seeds was determined by the tumor mass and the median number was $30 \mathrm{mCi} / \mathrm{cm} 2$. To protect the gastric and transverse colon mucosa from excessive irradiation, an omental fat pad was placed over the implanted vol- ume. Whether biliodigestive anastomosis or gastric bypass was indicated was dependent on the presence of obstruction of tumor of bile duct or duodenum

\section{Procedure for PD}

PD was performed on pancreatic cancer patients who met radiologically resectable or borderline resectable criteria as previously described ${ }^{7}$. Before surgery, distal metastasis and the position and margins of the mass were verified. The gallbladder and the complete lesions were transected, then pancreaticojejunal anastomosis, cholangioenterostomy gastrointestinal anastomosis, or both were completed (Table 1). Pancreatic drainage (before January 2012) or intra-abdominal drain (after January 2012) was applied to all patients. The levels of albumin and bilirubin in the blood were measured daily.

\section{Postoperative management}

Following surgery, all patients were transferred to the surgical intensive care unit (ICU) for postoperative recovery and monitoring. Discharge from the ICU was based on each patient's postoperative progress and was at the discretion of an independent attending ICU physician. Follow-up liver function tests were repeated on days 1,5 , and 10 following surgery. If ascites was suspected, diuretics were administered intravenously along with albumin supplementation, and abdominal ultrasonography or computed tomography was used to monitor the resolution of ascites. Patients were discharged from the hospital in the absence of any clinically significant events, and were followed up at 3-month intervals during the first year and at 6-month intervals thereafter. Follow-up tests included routine hematological, biochemical, and serological tests as well as abdominal CT scans.

\section{Statistical analysis}

The differences between ${ }^{125} \mathrm{I}$ seed implantation and pancreaticoduodenectomy treatments were analyzed by t-test using SPSS 19.0 software.

\section{Results}

\section{Surgical outcomes}

There were obvious differences between the 125I seed implantation and PD treatment groups with regard to operative time, bleeding, postoperative liver function, times for resuming bowel movement and normal diet, complications, and medical costs (Table 2). Compared with the PD procedure, ${ }^{125}$ I seed implantation resulted in significantly shorter operative time, less bleeding, higher albumin, less time to bowel movement and normal feeding, lower risk of complications, and lower medical costs. However, the dif- 
ference was not significant statistically in survival rate , overall response rate, local control rate and pain relief rate between two groups.

In 125I-implanted patients, 6 patients suffered postoperative complications, including 4 cases of pancreatic fistula (based on amylase value of drainage fluid) and 2 cases of respiratory failure; no deaths occurred during hospitalization. In PD-treated patients, 20 patients experienced postoperative complications, including 3 cases of wound infection, 4 cases of secondary surgery, 4 cases of gastrointestinal bleeding, 4 cases of pancreatic fistula, and 5 cases of respiratory failure, and 2 patients died during hospitalization.

Table 2. Clinicopathological parameters of all patients in the two groups.

\begin{tabular}{|c|c|c|c|}
\hline & \multicolumn{3}{|l|}{ Treatment } \\
\hline & $\begin{array}{l}{ }^{125} \text { I seed implanta- } \\
\text { tion }\end{array}$ & PD & $P$-value \\
\hline Operative time (min) & $43.7 \pm 10.9$ & $242.3 \pm 30.9$ & $<0.001$ \\
\hline Bleeding $(\mathrm{mL})$ & $21.6 \pm 3.3$ & $101.4 \pm 13.0$ & $<0.001$ \\
\hline Albumin (day 3, g/L) & $35.2 \pm 3$ & $26.3 \pm 2.2$ & $<0.001$ \\
\hline Albumin (day 7, g/L) & $38.4 \pm 4$ & $30.4 \pm 3$ & $<0.001$ \\
\hline Bilirubin (day $3, \mu \mathrm{mol} / \mathrm{L}$ ) & $222.9 \pm 19$ & $219.5 \pm 12$ & 0.41 \\
\hline Bilirubin (day $7, \mu \mathrm{mol} / \mathrm{L})$ & $67.2 \pm 8.4$ & $64.8 \pm 10$ & 0.322 \\
\hline Bowl movement $(\mathrm{d})$ & 2 & 3 & $<0.001$ \\
\hline Time to feeding (d) & $4.9 \pm 0.8$ & $8 \pm 1.7$ & $<0.001$ \\
\hline Complications (\%) & $20 \%$ & $66.7 \%$ & 0.0007 \\
\hline Medical cost $(\times 1,600$ USD $)$ & $4.95 \pm 0.5$ & $7.9 \pm 0.8$ & $<0.001$ \\
\hline Overall response rate $(\%)$ & 90 & 88 & 0.42 \\
\hline Local control rate(\%) & 94 & 92 & 0.36 \\
\hline Pain relief rate $(\%)$ & 99 & 98 & 0.326 \\
\hline $\begin{array}{l}\text { Mortality during hospitali- } \\
\text { zation }\end{array}$ & 0 & $6.7 \%$ & 0.495 \\
\hline
\end{tabular}

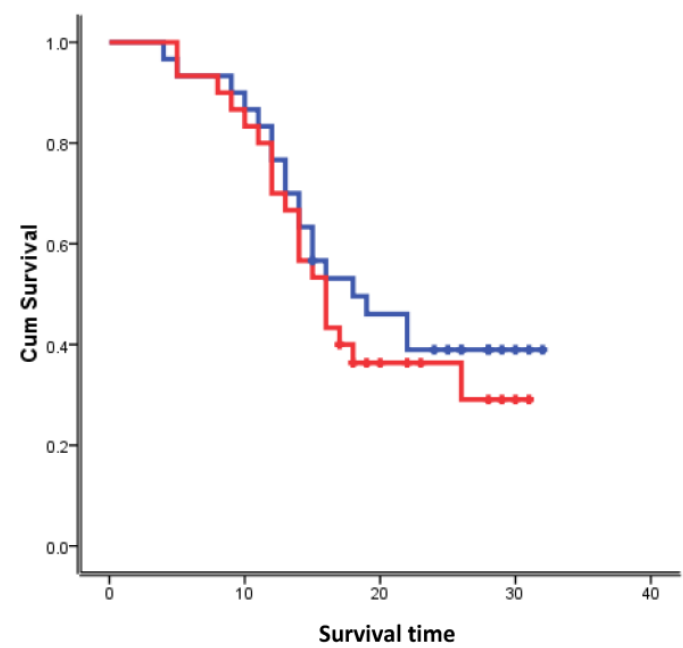

Treatment $\rightarrow P D$ $\rightarrow 1251$ $\mp$ PD-censored

\section{Follow-up and survival outcomes}

The follow-up time for all patients was between 1 month and 3 years, with a median of 1.5 years. As of September 2013, regarding the patients in the 125I-implanted group, 12 had survived, and 18 had died, and the median survival time was 16 months. In the PD-treated group, 16 patients had survived, 14 had died, and the median survival time was 18 months. The difference in the median survival time between the two treatments was not statistically significant (Figure 1).

\section{Discussion}

Since approximately $75 \%$ of all pancreatic carcinomas occur within the head or neck of the pancreas, it is difficult to diagnose pancreatic cancer in the early stage because of its anatomical location and atypical symptoms ${ }^{1,2}$. Most pancreatic cancers are diagnosed in the late stage after the patient presents with acute abdominal pain, lower back pain, or painless jaundice. At this stage pancreatic cancer is easily diagnosed by imaging-ultrasound, enhanced computed tomography, or magnetic resonance imaging. If the lesions are resectable, PD is still the first choice for pancreatic cancer treatment $t^{4,8}$, although there are other treatment methods, such as chemotherapy, palliative surgery, and radiofrequency ablation et al. However, PD has disadvantages that include great surgical trauma, a high incidence of complications, and high medical costs 9,10, and therefore many pancreatic cancer patients refuse to undergo PD treatment. ${ }^{125} \mathrm{I}$ seed implantation has been successfully applied to treat pancreatic cancer patients ${ }^{5,6}$, and is a potential option for patients who refuse PD or for whom PD is not appropriate. Because the comparative effects and side effects of PD and 125I seed implantation in the treatment of pancreatic cancer have not been documented, in this study we compared the advantages and disadvantages between these two procedures. The inhibiting effect on tumor growth of implanting ${ }^{125}$ I seeds into cancer lesions is more direct and obvious than that of external radiotherapy. Based on previous case reports and this study, ${ }^{125}$ I seed implantation can obviously inhibit tumor growth in pancreatic cancer and can completely eliminate lesions in some patients 5,6,6,11. Compared with the PD procedure, ${ }^{125}$ I seed implantation carries a greater risk of recurrence of tumor because lesion removal can be incomplete. Although in the present study the risk of pancreatic cancer recurrence between the two procedures was not compared, there was no significant difference in the median survival time. Besides, Bartllett et al also reported that Palliative bypass for advanced pancreatic cancer is associated with a high rate of morbidity and mortality. In select patients, this 
risk may be prohibitive. Patient selection reflecting predictors of morbidity and mortality may allow for improved outcomes ${ }^{12}$. This indicated that in specific patients, palliative operation is still a good option.

The PD procedure entails great surgical trauma, a high possibility of complications, increased risk of pancreatic fistula and death, and high medical costs ${ }^{13}$, 14. Compared with the PD procedure, ${ }^{125} \mathrm{I}$ seed implantation has many advantages: shorter operative time, less bleeding, faster recovery, shorter hospitalization, and lower medical cost. Because of the high risk and uncertain efficacy of the PD procedure, many patients and their family members prefer to choose a conservative therapy like ${ }^{125}$ I seed implantation rather than the radical surgery of the PD procedure. Compared with ${ }^{125}$ I seed implantation, in the present study the PD procedure did not statistically increase survival time, and therefore ${ }^{125}$ I seed implantation can be considered a viable choice for late-stage patients or patients with financial problems.

However, there are a few limitations in this study. First, this study is a retrospective and the results should be verified by prospective data. In addition, the sample size is small, reducing its statistical power. Finally, the follow-up period should be prolonged to collect the data regarding tumor recurrence.

This small study provides strong evidence of the advantages of ${ }^{125}$ I seed implantation for treating pancreatic cancer, with fewer traumas, faster recovery, and lower medical costs than the more commonly used PD procedure.

\section{Conclusion}

The ${ }^{125} \mathrm{I}$ seed implantation for advanced pancreatic cancer is a feasible, effective, and safe technique to delay tumor growth and prolong life expectancy for patients. This method avoided resected irrelevant organs, which reduced the volume of intraoperative blood loss, enhanced rapid postoperative recovery, and reduced risk of pancreatic risk, mobidity and morality of patients. A long-time survival follow-up study is ongoing in our institution to determine the effects on oncologic safety and survival of the ${ }^{125}$ I seed implantation method in patients with advanced pancreatic cancer who weren't indications of whipple's operation or didn't accept whipple's operation.

\section{Competing Interests}

The authors have declared that no competing interest exists.

\section{References}

1. Klein AP. Identifying people at a high risk of developing pancreatic cancer. Nat Rev Cancer. 2013 ;13(1):66-74.

2. Majumder S, Chubineh S, Birk J. Pancreatic cancer: an endoscopic perspective. Expert Rev Gastroenterol Hepatol. $2012 ; 6(1): 95-103$
3. Lin JW, Cameron JL, Yeo CJ, Riall TS, Lillemoe KD. Risk factors and outcomes in postpancreaticoduodenectomy pancreaticocutaneous fistula. J Gastrointest Surg. 2004;8(8):951-9.

4. Michalski CW, Weitz J, Büchler MW. Surgery insight: surgical management of pancreatic cancer. Nat Clin Pract Oncol. $2007 ; 4(9): 526-35$.

5. Wang JJ, Jiang YL, Li JN, Tian SQ, Ran WQ, Xiu D: Intraoperative ultrasound-guided iodine-125 seed implantation for unresectable pancreatic carcinoma. J Exp Clin Cancer Res 2009, 28:1-6.

6. Wang H, Wang J, Jiang Y, Li J, Tian S, Ran W, Xiu D, Gao Y. The investigation of $125 \mathrm{I}$ seed implantation as a salvage modality for unresectable pancreatic carcinoma. J Exp Clin Cancer Res. 2013;32(1):106.

7. Turley RS, Peterson K, Barbas AS, Ceppa EP, Paulson EK, Blazer DG 3rd, Clary BM, Pappas TN, Tyler DS, McCann RL, White RR. Vascular surgery collaboration during pancreaticoduodenectomy with vascular reconstruction. Ann Vasc Surg. $2012 ; 26(5): 685-92$.

8. Figueroa-Barojas P, Bakhru MR, Habib NA, Ellen K, Millman J, Jamal-Kabani A, Gaidhane M, Kahaleh M. Safety and efficacy of radiofrequency ablation in the management of unresectable bile duct and pancreatic cancer: a novel palliation technique. J Oncol. 2013;2013:910897. doi: 10.1155/2013/91089.

9. Bhosale P, Fleming J, Balachandran A, Charnsangavej C, Tamm EP. Complications of Whipple surgery: imaging analysis. Abdom Imaging. 2013 38(2):273-84.

10. Vladov N, Takorov I, Kazarov K, Mutafchiiski V, Vasilevski I, Sergeev S, Odiseeva E. Surgical potentialities for the treatment of pancreatic cancer. Hepatogastroenterology. 2012;59(113):280-3.

11. Fegrachi S, Besselink MG, van Santvoort HC, van Hillegersberg R, Molenaar IQ. Radiofrequency ablation for unresectable locally advanced pancreatic cancer: a systematic review. HPB (Oxford). 2013. doi: 10.1111/hpb.12097.

12. Bartlett EK1, Wachtel H, Fraker DL, Vollmer CM, Drebin JA, Kelz RR, Karakousis GC, Roses RE. Surgical Palliation for Pancreatic Malignancy: Practice Patterns and Predictors of Morbidity and Mortality. J Gastrointest Surg. 2014; [Epub ahead of print]

13. Wolfgang CL, Pawlik TM. Pancreaticoduodenectomy: time to change our approach? Lancet Oncol.2013;14(7):573-5.

14. Gerstenhaber F, Grossman J, Lubezky N, Itzkowitz E, Nachmany I, Sever R, Ben-Haim M, Nakache R, Klausner JM, Lahat G.Pancreaticoduodenectomy in elderly adults: is it justified in terms of mortality, long-term morbidity, and quality of life? J Am Geriatr Soc. 2013;61(8):1351-7. 